\title{
Oil and medicine: Alberta MDs gain support
}

W hen Mike Labrecque told his doctor that he believed his symptoms were linked to emissions from the oil wells around his house, the doctor promptly stopped treating the 60-year-old man.

"The physician stood up and told him you need a lawyer, not a doctor and basically told him to leave," recalls Mike's son Brian Labrecque, whose family lives in the Peace River area of northern Alberta. "We were shocked. From that point on we had to find other physicians who could treat my father."

"Physicians are frankly afraid to diagnose health conditions linked to the oil and gas industry," stated Margaret Sears, an Ottawa, Ontario-based consultant in toxicology and environmental health, in her Jan. 13 report prepared for hearings by the Alberta Energy Regulator (AER), the oil industry's governing body, into "human health effects associated with emissions and odours from heavy oil operations in the Peace River area."

Peace River-area physicians can take heart from the AER's Report of Recommendations on Odours and Emissions in the Peace River Area, which states that there may be a link between residents' symptoms and odours from heavy oil operations in the area and calls on the industry to reduce odour to "the extent possible." In addition, both the Alberta Medical Association (AMA) and the Alberta College of Physicians and Surgeons have now spoken out in support of physicians who may feel too intimidated to advocate for these patients.

AMA President Dr. Allan S. Garbutt said he told a leading physician in the area to let other doctors know that there is support available for them from the association in the event of intimidation. "Advocacy is a key function for physicians and must be protected," said Garbutt. "If any of our members feel they are being intimidated, there are a variety of ways we can support and assist them to help deal with that situation."

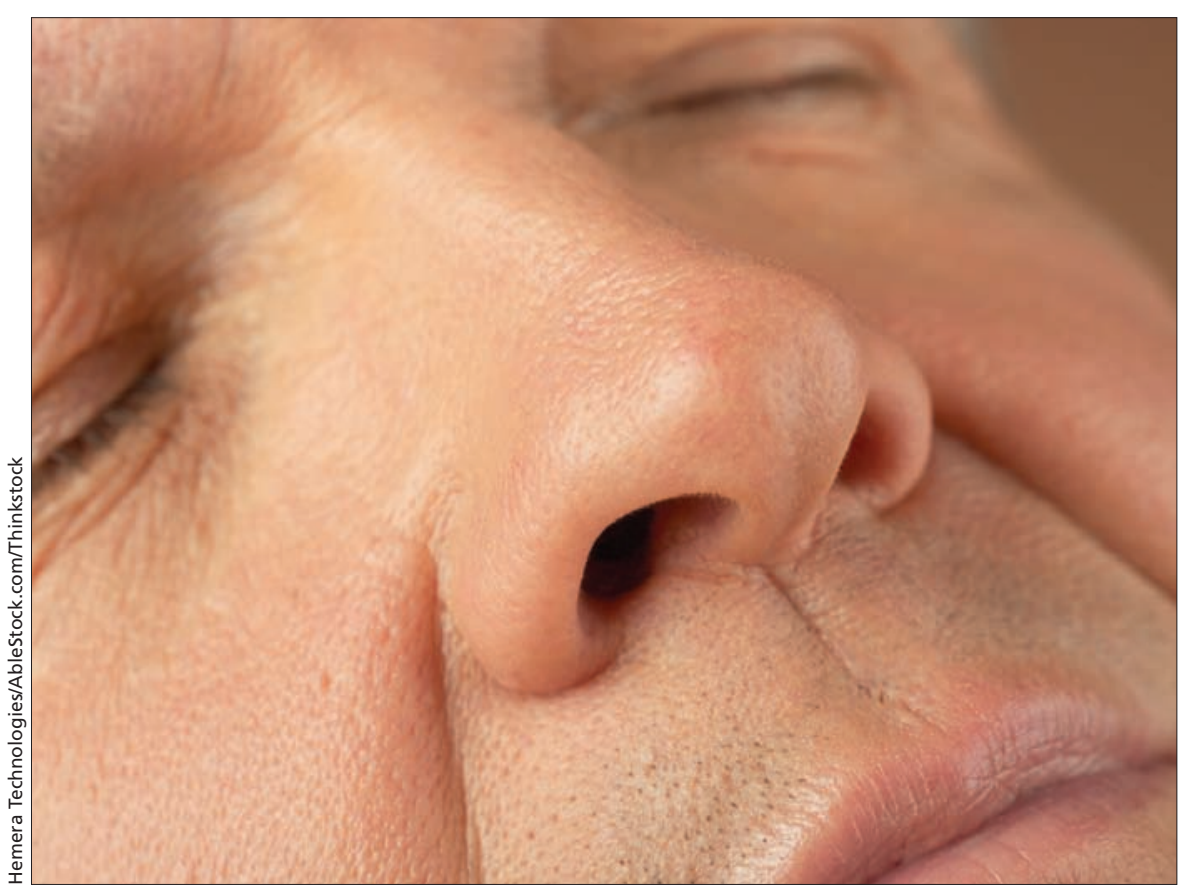

A new report says there may be a link between Peace River, Alberta, residents' symptoms and odours from heavy oil operations in the area.

Dr. Trevor Theman, registrar at the Alberta College of Physicians and Surgeons, said doctors shouldn't be afraid to advocate for their patients, adding however that "it should be responsible advocacy, meaning that the information should be presented fairly and should be scientifically based."

Doctors' reluctance — or fear, as Sears notes - may stem at least in part, from the case of Dr. John O'Connor. In 2007, Health Canada laid four complaints of professional misconduct with the Alberta college against the Fort Chipewyan physician after he suggested a link between oil sands development and elevated rates of cancer in his northern Alberta community. O'Connor was later cleared of all the complaints by the college.

Although no disciplinary action was ever taken against O'Connor by the college, the AER's new report indicates that one reason physicians may feel intimidated when it comes to treating these patients is the O'Connor case.

"High profile consequences of researchers' and physicians' findings of harm potentially linked to the petroleum industry have driven professionals not to 'go there'," adds Sears.

Mike Labrecque is just one of several people who have left their homes in Reno, south of Peace River, because, they say, emissions from bitumen processing are causing them health problems including headaches, sinus infections, vomiting, dizziness and throat congestion.

The AER Mar. 31 report confirmed that there may be a link between residents' symptoms and odours from heavy oil operations in the area. "Odours caused by heavy oil operations in the Peace River area need to be eliminated to the extent possible as they have the potential to cause some of the health symptoms of area residents," stated the report.

The AER panel that authored the report recommended that further study be undertaken to access the link between odours and health effects in the area, and that companies operating in the area install vapour recovery units to capture gas produced in their operations. 
On Apr. 15 the AER accepted the recommendations of the panel and announced that as of Aug. 15, all existing heavy oil and bitumen operations in the area must capture produced gas rather than releasing it into the environment.

In a press conference, Carol Crowfoot, the vice-president of regulatory operations for the regulator, said the measure was aimed at reducing emissions in the area. "The AER has accepted the work and the participation of everyone in that [Peace River] proceeding and believes that the recommendations are certainly valid and will go a long way to hopefully eliminate the odour and emissions in that area," said Crowfoot. "If there is found to be noncompliance, enforcement actions will occur and could also result in the shutting of a well or a facility."

Baytex Energy was unavailable for comment but in a press release, company President and Chief Executive Officer Jim Bowzer said work was underway to capture tank top vapours from all existing and future well sites. "Baytex's gas conservation activities and plans are consistent with the AER initiatives announced today," stated Bowzer.

In its report, the AER panel also recommended that Alberta Health take steps to link local physicians to specialists in environmental health.

Both Garbutt and Theman say the lack of knowledge may be another reason that physicians may shy away from treating patients with symptoms linked to oil exposure.

"If a patient had come to me and asked me to link symptoms to oil and gas exposure I would have not known how to do so," says Theman. "I would have not known what tests to do and how to prove that."

"Most physicians receive little training in assessing ongoing exposures," adds the AMA's Garbutt.

Whatever is behind physician hesitation to treat such patients, it may have resulted in patients who are reluctant to tell their whole story.

When searching for a new doctor, Mike Labrecque's family advised him not to talk about his belief that his symptoms are caused by exposure to oil emissions.

"We made sure to tell my father, 'Don't tell [the new doctor] it's due to the air quality or the emissions because we don't want you to get dismissed," " said his son, Brian Labrecque. Jocelyn Edwards, Calgary, Alta.

CMAJ 2014. DOI:10.1503/cmaj.109-4801 